\title{
recildunds
}

Revista Cientifica Mundo de la Investigación y el Conocimiento

\author{
Mariuxi Stefanía Macías Cedeño a ; Gabriela Ivonne Cedeño López ${ }^{\text {b; }}$ Shirley \\ Johanna Arévalo Bravo ${ }^{c}$; Martha Isabel Arcos Gutierrez ${ }^{d}$
}

Etiología y factores de riesgo de la queratitis herpética

Etiology and risk factors of herpetic keratitis

Revista Científica Mundo de la Investigación y el Conocimiento. Vol. 3 núm. 4., diciembre, ISSN: 2588-073X, 2019, pp. 606-623

DOI: 10.26820/recimundo/3.(4).diciembre.2019.606-623

URL: http://recimundo.com/index.php/es/article/view/684

Código UNESCO: 3205 Medicina Interna

Tipo de Investigación: Artículo de Revisión

(C) RECIMUNDO; Editorial Saberes del Conocimiento, 2019

Recibido: 15/09/2019

Aceptado: 23/11/2019

Publicado: 30/12/2019

Correspondencia: karinaborjaa@gmail.com

a. Médico; Instituto Ecuatoriano de Seguridad Social Guayaquil, Ecuador; msmaciasc@iess.gob.ec

b. Médico; Instituto Ecuatoriano de Seguridad Social Guayaquil; Guayaquil, Ecuador; gcedenol@iess.gob.ec

c. Médico; Ministerio de Salud Pública; Guayaquil, Ecuador; shirley.arevalo@ distrito09d16.saludzona5.gob.ec

d. Médico; Ministerio de Salud Pública; Guayaquil, Ecuador; marthica12@msn.com 


\section{Etiología y factores de riesgo de la queratitis herpética}

Vol. 3, núm. 4., (2019)

Mariuxi Estefanía Macías Cedeño; Gabriela Ivonne Cedeño López; Shirley Johanna Arévalo Bravo; Martha Isabel Arcos Gutierrez

\section{RESUMEN}

La queratitis herpética sigue siendo la principal causa infecciosa de úlceras corneales y ceguera en todo el mundo. El objetivo del presente trabajo se centra en exponer, principalmente, sobre la etiología y los factores de riesgo asociados a la queratitis herpética transmitida por el virus de herpes simple, así como también otros aspectos fundamentales relacionados, tales como: conceptos y tipos de queratitis herpéticas, si menos cabo de una breve mención respecto a su diagnóstico y tratamientos. Fue posible concluir que, básicamente, la queratitis por herpes simple por lo general deviene de la recurrencia de la primo infección ocular por herpes simple (VHS-1 o VHS-2); que este tipo de virus contribuyen principalmente en las infecciones causantes de enfermedades en humanos y, especialmente, de morbilidad ocular; que de la etiología es sencillo comprender lo fácil y casi inevitable que es el contagio del VHS-1 para los humanos, su inicial asintomatología asociada y su eventual reactivación mediante estímulos igualmente casi incontrolables; y por último, que respecto a los factores de riesgo, se cree es igualmente complicado pretender mantenerse exentos de estos, puesto que, casi en su totalidad, no dependerán en mayor medida de la acción humana sino de otras variales no inherentes a su absoluto control.

Palabras Claves: Infección resistente; Cornea; Herpesvirus; Ceguera; Infección Corneana 


\section{Etiología y factores de riesgo de la queratitis herpética}

Vol. 3, núm. 4., (2019)

Mariuxi Estefanía Macías Cedeño; Gabriela Ivonne Cedeño López; Shirley Johanna Arévalo

Bravo; Martha Isabel Arcos Gutierrez

\section{ABSTRACT}

Herpetic keratitis remains the leading infectious cause of corneal ulcers and blindness worldwide. The objective of the present work is focused on exposing, mainly, on the etiology and risk factors associated with herpetic keratitis transmitted by the herpes simplex virus, as well as other related fundamental aspects, stories such as: concepts and types of herpetic keratitis, at least after a brief reference regarding its diagnosis and treatments. It was possible to conclude that, significantly, herpes simplex keratitis usually from the recurrence of recurrence of ocular herpes simplex infection (HSV-1 or HSV-2); that this type of virus mainly affects infections causing diseases in humans and, especially, ocular morbidity; that the etiology is easy to understand how easy and almost inevitable is the contact of HSV-1 for humans, its associated initial asymptomatology and its eventual reactivation by equally almost uncontrollable stimuli; and finally, that with respect to risk factors, it is believed that it is equally difficult to pretend to remain exempt from them, since, almost entirely, it does not depend to a greater extent on human action but on other varials not inherent in its absolute control .

Keywords: Resistant infection; Cornea; Herpesvirus; Blindness; Corneal infection 


\section{Etiología y factores de riesgo de la queratitis herpética}

Vol. 3, núm. 4., (2019)

Mariuxi Estefanía Macías Cedeño; Gabriela Ivonne Cedeño López; Shirley Johanna Arévalo

Bravo; Martha Isabel Arcos Gutierrez

\section{Introducción.}

"La queratitis herpética sigue siendo la principal causa infecciosa de úlceras corneales y ceguera en todo el mundo" (Ahmad \& Patel, 2019).

Harrison \& Paga (2016) dicen que la queratitis herpética es una infección viral del ojo causada más frecuentemente por el virus del herpes simple (VHS), habiendo de estos dos tipos, el Tipo I, que es el más común y afecta principalmente a la cara, generalemente causando el "herpes labial". y el Tipo II, que es transmisible sexualmente y que, por ende, infecta los genitales. Cualesquiera de estos dos tipos de herpes pueden propagarse en los ojos y ocasionar una infección, siendo el de tipo I la causa más común de infecciones en los ojos.

Roat (2018) la define como una la infección corneana causada por el virus herpes simple que puede afectar el iris. Los signos y síntomas incluyen sensación de cuerpo extraño, lagrimeo, fotofobia e hiperemia conjuntival. Las recurrencias pueden dar lugar a hipoestesia, ulceración, cicatrización permanente de la córnea y disminución de la visión

Por su parte, Espinosa, Tandón, \& Medina (2016) aseguran que "El VHS tipo 1 produce infecciones oculares con mayor frecuencia y su recurrencia es una de las principales causas de ceguera en países industrializados, mientras que las infecciones por el VHS tipo 2 suelen ser menos frecuentes, pero más graves." (p. 21).

De la misma manera estos expertos aseguran que, es muy común que los seres humanos se contagien con el virus herpes simple (VHS). De hecho, refieren que, por ejemplo, en la 


\section{Etiología y factores de riesgo de la queratitis herpética}

Vol. 3, núm. 4., (2019)

Mariuxi Estefanía Macías Cedeño; Gabriela Ivonne Cedeño López; Shirley Johanna Arévalo

Bravo; Martha Isabel Arcos Gutierrez

población adulta, se ha estimado que no menos de un $90 \%$ de esto le han sido detectados anticuerpos positivos para dicho virus.

Con el criterio anterior coincide García (2018), quien además detalla que se ha estimado que el impacto global de esta enfermedad se calcula entre 1 y 1,5 millones de casos, sim embargo, los datos reales y precisos aún no se han podido determinar. Así mismo dice que, en los países en desarrollos, es posible que esta enfermedad sea ocasionada principalmente por estrés, falta de acceso al tratamiento y mayor exposición a rayos ultravioleta. (p. 108, 109).

Cabe destacar que la queratitis herpética no solamente puede ser causada por el virus del herpes simple (VHS), sino también por otros virus tales como el virus de la varicela zóster (VZV) y el citomegalovirus (CMV).

Respecto al diagnóstico, Moya (2015) refiere que, el cálculo de su aparición, la distribución y el aspecto característico de las lesiones son fundamentales, puesto que esto podría bastar a la hora de la determinación de un análisis clínico, sin menoscabo de esto, ocurren situaciones especiales en las que se refieren algunas pruebas de laboratorio que permitan identificar el origen del proceso y establecer un diagnostico virológico exacto. De la misma manera aclaró también que, son anómalas las manifestaciones clínicas por infección primaria por VHS tipo 1, y ocurren con mayor frecuencia en las primeras etapas de la vida (p. 15, 16).

En el mismo sentido, Mayo Clinic (2019); quien teniendo en consideración la variedad de cuadros clínicos de este enfermedad y, por ende, la trascendencia de un adecuado diagnóstico para no confundir esta patología con cualquier otra enfermedad ocular con signos similares, indica que el diagnóstico de la queratitis herpética, generalmente incluye: examen ocular 


\section{Etiología y factores de riesgo de la queratitis herpética}

Vol. 3, núm. 4., (2019)

Mariuxi Estefanía Macías Cedeño; Gabriela Ivonne Cedeño López; Shirley Johanna Arévalo Bravo; Martha Isabel Arcos Gutierrez

(agudeza visual), examen con una mini linterna (comprobación de la reacción, el tamaño y otros factores de la pupila, o también, determinación de la extensión y el carácter de las irregularidades y las úlceras superficiales de la córnea mediante la aplicación de un tinte especial en el ojo afectado); examen con lámpara de hendidura, y/o análisis de laboratorio, entre estas la de Reacción en cadena de la polimerasa (PCR), según Pérez (2014, pág. 70).

En cuanto al tratamiento, principalmente se realiza con agentes antivíricos tópicos y, en ocasiones son necesarios, los sistémicos. De todas maneras García (2018) afirma que los HEDS (Herpetic Eye Disease Study) todavía son asumidos como un patrón de referencia para el tratamiento de la enfermedad herpética del segmento anterior.

En cuanto a la queratitis herpética se ha visto una recuperación espontánea en el $50 \%$ de los pacientes, sin embargo, cuando se adiciona tratamiento con antivirales lo que se busca es disminuir la sintomatología, la pérdida visual y la tasa de recurrencia. Por último, cabe destacar que en el 2017 la Comisión Europea de Medicamentos y en el 2018 la FDA autorizaron el uso de Cenegermin que es una forma recombinante del factor de crecimiento neural (NGF), presente en la superficie ocular, esencial para el crecimiento y mantenimiento de las neuronas simpáticas y sensitivas de la córnea.

En el caso de infecciones resistentes al aciclovir, y su consecuente ganciclovir, el criterio de Parro et al. (2018) es el uso de foscarnet en forma de colirio. (pág. 334).

La presente entrega se centra en hacer referencia de algunas fuentes vigentes que expliquen lo relativo a la etiología y factores de riesgo de la queratitis herpética ocasionada por 


\section{Etiología y factores de riesgo de la queratitis herpética}

Vol. 3, núm. 4., (2019)

Mariuxi Estefanía Macías Cedeño; Gabriela Ivonne Cedeño López; Shirley Johanna Arévalo Bravo; Martha Isabel Arcos Gutierrez

el virus de herpes simple. Sin embargo, se expondrán brevemente algunas acepciones actuales, así como también su forma de diagnóstico, tratamiento y tipos de queratitis herpética.

\section{Materiales y Métodos.}

El presente trabajo, concebido en base a un diseño documental, y además en el marco de una metodología de revisión, se enfoca, por una parte, en la creación de un material bibliográfico nuevo, y por la otra, referir algunos criterios recientes o vigentes de los distintos tratadistas en cuanto a la etiología y factores de riesgo de la queratitis herpética.

Entre las bases de datos consultadas resaltaron la de: Centro Nacional de Información sobre Biotecnología (NCBI), Biblioteca Virtual de la Salud (BVS), National Institutes of Health (NHI), SciELO, MedlinePlus, BASE, Dialnet, entre otras. Como términos de búsqueda se utilizaron las expresiones "queratitis herpética" y "queratitis por herpes simple", a los que seguidamente se le aplicaron criterios de selección tales como: idioma español (e inglés en algunos casos); publicación entre 2009 y 2019 (ambos inclusive), salvo algunas excepciones; acceso completo y abierto; en materia de salud y medicina; estudios referidos a humanos; tipo de bibliografía, artículos científicos, revisiones sistemáticas, guías clínicas, e-books, ensayos clínicos, estudios de cohorte, estudios o reportes de casos, consensos, protocolos, tesis de grado, posgrado y doctorado, noticias científicas, boletines y/o folletos de instituciones oficiales o privadas de reconocida trayectoria en el área de la salud, medicina o científico académica, y demás, monografías y otros documentos que, a criterio propio, mostraran información de interés en base a la observación de la evidencia científica referida en sus contenidos. Este proceso arrojó 


\section{Etiología y factores de riesgo de la queratitis herpética}

Vol. 3, núm. 4., (2019)

Mariuxi Estefanía Macías Cedeño; Gabriela Ivonne Cedeño López; Shirley Johanna Arévalo Bravo; Martha Isabel Arcos Gutierrez

resultados que en promedio oscilaron entre 5 y 79 enlaces a fuentes de información bibliográficas.

De la mima manera fueron adelantadas otras búsquedas menores sin considerar la aplicación cualquier otro criterio de descarte, ya que se requirió encontrar información complementaria que independientemente de su origen o época de publicación, es considerada igualmente vigente y relevante para este tema. Es a partir de entonces que se procedió con la lectura crítica y análisis interpretativo del cúmulo de información definitivamente recabado, que también fue adoptada como evidencia. El resultando de todo este proceso es la fundamentación de la argumentación aquí expuesta, que, por cierto, en todo momento fue hecha de manera conjunta.

En definitiva, se considera igualmente valioso aclarar que, la inclusión y exclusión de cada una de las citas y referencias hechas en la presente entrega fue definida también mediante el consenso grupal, y de la misma manera fueron resueltas las opiniones disímiles.

\section{Resultados.}

La queratitis herpética es una enfermedad viral que compromete la córnea producto de la infección por herpes virus, tales como virus de herpes simple (HSV) o virus de varicela zoster (HZV), siendo más frecuente la infección por el primero de éstos encontrándose a su vez constituido por dos serotipo; tipo I causante del herpes labial y tipo II causante del herpes genital. Esta enfermedad representa una de las principales causas de opacificación corneal, pérdida de la visión e incluso de trasplante corneal en EEUU. (Cueva \& Arana, 2010, pág. 46). 


\section{Etiología y factores de riesgo de la queratitis herpética}

Vol. 3, núm. 4., (2019)

Mariuxi Estefanía Macías Cedeño; Gabriela Ivonne Cedeño López; Shirley Johanna Arévalo Bravo; Martha Isabel Arcos Gutierrez

Muñoz \& Morillo (2017) argumentan que la queratitis epitelial aparece tras el progreso de una queratoconjuntivitis, misma que comúnmente se origina "por reactivación del HSV-1 desde el ganglio trigémino y de forma unilateral." Y que se presenta con "conjuntivitis folicular, fotofobia, dolor y secreción" e igualmente pudiendo presentarse "quemosis, vesículas y edema en el borde del párpado y adenopatía preauricular." En la queratitis epitelial emergen "lesiones puntiformes o punctata en la capa superficial de la córnea que posteriormente se ramifican dando lugar a las úlceras dendríticas como signo patognomónico, que se evidencian con la tinción de fluoresceína."

Se manifiesta con visión borrosa y fotofobia grave. Cura en 2 a 3 semanas. Después de la infección primaria, de un 33 a un $80 \%$ de los pacientes pueden tener recurrencias, con reaparición de las úlceras y lesión del estroma profundo o queratitis estromal, siendo la causa más frecuente de ceguera unilateral de origen corneal a nivel mundial. En estos casos la curación puede prolongarse a un mes. El deterioro visual se debe al daño viral directo y a la respuesta inflamatoria e inmune, que se incrementa con las recurrencias.

\section{Tipos de queratitis herpética}

Para el Servicio de Oftalmología del Hospital Universitario Sanitas La Moraleja (2018), los tipos de queratitis herpética son: la Epitelial, la cual se caracteriza por tener un tiempo de incubación entre 1 y 28 días, afectando únicamente al epitelio de la córnea. Cuando se presenta por primera, vez lo hace de manera leve y asintomática; la estromal inmune (intersticial o disciforme), que surge luego de un primer episodio o cuando se ha presentado de manera 


\section{Etiología y factores de riesgo de la queratitis herpética}

Vol. 3, núm. 4., (2019)

Mariuxi Estefanía Macías Cedeño; Gabriela Ivonne Cedeño López; Shirley Johanna Arévalo Bravo; Martha Isabel Arcos Gutierrez

recurrente; y la estromal necrotizante: que representa la forma más severa ya que pudiera derivar en ceguera.

En el mismo orden de ideas se ha encontrado una diferenciación expuesta por García (2018) quien detalla que, lo que anteriormente se denominaba queratitis inmune ahora es queratitis no necrotizante, misma que ocurre en $20 \%$ de los casos de pacientes con enfermedad crónica o recurrente. Agrega que en estos casos es evidente una inflamación estromal focal, multifocal o difusa que puede ser asociada a uveítis anterior, no obstante, en este mismo tipo de condiciones no hay historia de compromiso del epitelio por lo que ha de encontrarse sano. "La inflamación puede ser crónica, recurrente o recrudescente llevando a cicatrización estromal, adelgazamiento, neovascularización y depósito de lípidos. Ocasionalmente se observa un anillo inmune o anillo de Wessely, que representa el complemento de precipitado antígeno-anticuerpo." También se refiere a la Endotelitis asociada a la queratitis estromal ocurre en tres formas: disciforme, difusa y linear.

La forma más común es la disciforme la cual se caracteriza por una lesión en forma de disco central o paracentral que compromete todo el estroma corneal dando una apariencia de vidrio esmerilado, asociado a la presencia de precipitados queráticos e iritis leve a moderada. La forma linear se caracteriza por la presencia de precipitados queráticos en forma serpiginosa que progresan desde el limbo hacia el centro de la córnea asociado a edema estromal y epitelial. En la mayoría de las ocasiones se acompaña de una elevación de la presión intraocular, aparentemente por una trabeculitis. (pág. 110-111). 


\section{Etiología y factores de riesgo de la queratitis herpética}

Vol. 3, núm. 4., (2019)

Mariuxi Estefanía Macías Cedeño; Gabriela Ivonne Cedeño López; Shirley Johanna Arévalo Bravo; Martha Isabel Arcos Gutierrez

Continúa el autor aludiendo al Síndrome iridocorneal endotelial, como otro tipo de queratitis herpética, diciendo que ocurre de manera unilateral asociado a edema corneal, corectopia y una alteración del trabéculo lo que genera un glaucoma secundario. Finalmente indica que, en los niños, la queratitis herpética es diferente a la de los adultos ya que, entre el 10 y el $21 \%$ de los casos se manifiesta bilateralmente y la respuesta inflamatoria es mucho mayor por lo que hay una mayor predisposición a la cicatrización corneal.

\section{Etiología}

Valverde (2017) explica que:

La persona se infecta con el VHS-1 al tomar contacto con el virus presente en las lesiones o las secreciones de individuos enfermos o de excretores asintomáticos. Principalmente infecta la piel y la mucosa facial, aunque también puede dar manifestaciones genitales y del SNC. El virus ingresa y se multiplica en la mucosa oral, generalmente, sin que se exprese clínicamente la infección (asintomática en un 90\%). Luego de la infección inicial en el epitelio, los virus contactan los terminales nerviosos sensitivos que inervan la zona y viajan por los axones hasta las neuronas ganglionares del trigémino, donde permanecen en estado de latencia. Frente a ciertos estímulos, como la luz ultravioleta, el estrés, un trauma local, la fiebre o u otra infección, el VHS-1 se reactiva, vuelve por los axones hasta el sitio inicial (o cercano a este) de la infección y se manifiesta como un herpes labial o es excretado en forma asintomática por la saliva. (pág. 213). 


\section{Etiología y factores de riesgo de la queratitis herpética}

Vol. 3, núm. 4., (2019)

Mariuxi Estefanía Macías Cedeño; Gabriela Ivonne Cedeño López; Shirley Johanna Arévalo Bravo; Martha Isabel Arcos Gutierrez

Nijm (2019) explica que:

La queratitis por VHS es causada por el virus del herpes simple, un virus de ADN bicatenario formado por una cápside con forma icosaédrica que rodea un núcleo de ADN y fosfoproteínas de cromatina viral. VHS I y VHS II se diferencian por antígenos específicos de virus. El VHS I generalmente afecta la región de la orofaringe, mientras que el VHS II generalmente involucra el área genital, aunque los estudios han demostrado que ambos virus pueden afectar cualquier ubicación. La enfermedad herpética ocular es causada con mayor frecuencia por HSV I, que se supone que tiene acceso a la córnea a través del contacto directo o a través del nervio trigémino por infección oral. La infección inicial generalmente permanece asintomática. Luego, el virus viaja a través de los axones nerviosos sensoriales para establecer una infección latente; en la enfermedad ocular, esto generalmente involucra el ganglio trigémino. El virus es capaz de reactivarse a lo largo de cualquier rama del ganglio trigémino, especialmente durante los estados inmunocomprometidos.

Por su parte, Ahmad \& Patel (2019), dicen que los responsables de la propagación de la enfermedad, son los siguientes factores etiológicos:

En la infección primaria:

- VHS-1: causa infección en la cara, labios y ojos. La afectación de la córnea se debe a una infección directa.

- VHS-2: infecta los genitales; sin embargo, puede transmitirse al ojo a través de secreciones infectadas, ya sea venéreamente o al nacer 


\section{Etiología y factores de riesgo de la queratitis herpética}

Vol. 3, núm. 4., (2019)

Mariuxi Estefanía Macías Cedeño; Gabriela Ivonne Cedeño López; Shirley Johanna Arévalo

Bravo; Martha Isabel Arcos Gutierrez

(conjuntivitis neonatal).

- Condiciones ambientales: la facilitación de la transmisión de HSV ocurre en condiciones de hacinamiento y falta de higiene.

\section{Reactivación:}

La infección primaria puede volverse latente, lo que puede reactivarse más adelante en la vida debido a una variedad de factores estresantes como fiebre, trauma, inmunosupresión, cambio hormonal y exposición a la radiación, etc.

La Academia Americana of Oftalmología de estados Unidos de América (AAO, por sus siglas en inglés), mediante la exposición de Harrison \& Pagan (2016) como revisores expertos, describen que:

Después de una infección original, el virus permanece en estado latente, viviendo en las células nerviosas de la piel o los ojos. Una recurrencia puede ser activada de varias maneras, incluyendo: estrés; exposición al Sol; fiebre; trauma en el cuerpo (como una lesión o cirugía); menstruación; ciertos medicamentos. Una vez que el herpes simple está presente en el ojo, por lo general infecta a los párpados, la conjuntiva (la membrana delgada y transparente de mucosa que recubre el interior de los párpados y la parte blanca del ojo), y la córnea (la ventana transparente, en la parte anterior del ojo).

Al respecto, el Colegio de Optometristas de Londres (2019) informa que la infección por el virus del herpes simple tipo 1 (VHS-1) generalmente infecta por encima de la cintura (labios, 


\section{Etiología y factores de riesgo de la queratitis herpética}

Vol. 3, núm. 4., (2019)

Mariuxi Estefanía Macías Cedeño; Gabriela Ivonne Cedeño López; Shirley Johanna Arévalo Bravo; Martha Isabel Arcos Gutierrez

cara, ojos) y la infección primaria generalmente se da en la infancia; luego el virus permanece latente en el ganglio trigémino. Cuando el virus se reactiva, viaja a lo largo de las ramas del nervio trigémino para causar infección local (por ejemplo, herpes labial o queratitis herpética). La infección por virus del herpes simple tipo 2 (VHS-2) generalmente infecta 'debajo de la cintura' y comúnmente se adquiere sexualmente, pero también puede ser una causa de queratitis herpética.

La infección ocular por VHS puede manifestarse como blefaroconjuntivitis, queratitis, iridociclitis o necrosis retiniana aguda. La forma más común es la queratitis epitelial, que representa del $50 \%$ al $80 \%$ de los casos. La infección ocular por HSV puede clasificarse en enfermedad primaria y recurrente.

Factores de riesgo

- Salud general deficiente, inmunodeficiencia, fatiga.

- Esteroides sistémicos o tópicos u otros fármacos inmunosupresores.

\section{Posibles factores agravantes:}

- Luz solar (UV), fiebre, calor o frío extremo.

- Infección (sistémica u ocular).

- Trauma (ocular)

- Historia de ataques previos de infección ocular por herpes simple (característica clave de diagnóstico).

- Enfermedad atópica severa. (Colegio de Optometrístas de Londres, 2019). 


\section{Etiología y factores de riesgo de la queratitis herpética}

Vol. 3, núm. 4., (2019)

Mariuxi Estefanía Macías Cedeño; Gabriela Ivonne Cedeño López; Shirley Johanna Arévalo Bravo; Martha Isabel Arcos Gutierrez

En este mismo sentido, Nijm (2019) aclara que los factores de riesgo para el desarrollo de VHS primario implican el contacto directo con lesiones infectadas, pero también pueden resultar como exposición a la diseminación viral asintomática. Además, agregó que los factores de riesgo que priorizan la reactivación de la enfermedad serían: la exposición a la luz solar, trauma, calor, menstruación, estrés, enfermedades infecciosas y estados inmunocomprometidos.

Otros factores de riesgo para la infección primaria por HSV referidos por la AAO (2013) han sido:

- Contacto personal cercano con una persona infectada

- Compartir utensilios, cepillos de dientes, etc. con una persona infectada.

\section{Conclusiones.}

Es destacable que, básicamente, la queratitis por herpes simple por lo general deviene de la recurrencia de la primo-infección ocular por herpes simple (VHS-1 o VHS-2), que a su vez pudo típicamente tratarse de una conjuntivitis inespecífica y autolimitada. De la misma manera resalta que este tipo de virus son quienes contribuyen principalmente en las infecciones causantes de enfermedades en humanos y, especialmente, de morbilidad ocular.

La evidencia científica ha dejado ver que es común que de los casos de enfermedad ocular herpética se encuentren estrechamente vinculados con el virus del herpes simple (aunque claro está que también representan cifras significativas el virus de la varicela zoster y citomegalovirus) sin menos cabo de otros tantos herpesvirus igualmente implicados en la enfermedad ocular. 


\section{Etiología y factores de riesgo de la queratitis herpética}

Vol. 3, núm. 4., (2019)

Mariuxi Estefanía Macías Cedeño; Gabriela Ivonne Cedeño López; Shirley Johanna Arévalo Bravo; Martha Isabel Arcos Gutierrez

Por último, de la etiología es sencillo comprender lo fácil y casi inevitable que es el contagio del VHS-1 para los humanos, su inicial asintomatología asociada y su eventual reactivación mediante estímulos igualmente casi incontrolables en su mayoría por el portador de dicho virus, y eso aparte de que algunos expertos asocian también aspectos medioambientales. En el mismo sentido e igualmente considerando las marcadas coincidencias entre los tratadistas respecto a los factores de riesgo, se cree que es igualmente complicado pretender mantenerse exentos de estos, puesto que, casi en su totalidad, no dependerán en mayor medida de la acción humana sino de otras variales no inherentes a su absoluto control, como podría ser: la amera en que reacciona el propio sistema inmune, la genética, las condiciones de salubridad exógenas, entre otros.

\section{Bibliografía.}

AAO. (Noviembre de 2013). Queratitis por herpes simple - América Latina. Obtenido de American Academy of Ophthalmology: https://www.aao.org/topic-detail/herpes-simplexkeratitis--latin-america

Ahmad, B., \& Patel, B. (18 de 08 de 2019). Queratitis por herpes simple. (StatPearls Publishing) Obtenido de StatPearls: ncbi.nlm.nih.gov/books/NBK545278/

Colegio de Optometrístas de Londres. (10 de 07 de 2019). Herpes Simplex Keratitis. Obtenido de The College of Optometrists: https://www.college-optometrists.org/guidance/clinicalmanagement-guidelines/herpes-simplex-keratitis-hsk-.html

Cueva, D., \& Arana, M. (2010). Queratitis herpética bilateral: Reporte de un caso. Acta Científica Estudiantil, 8(2), 45-47.

Espinosa, G., Tandón, L., \& Medina, F. (2016). Queratitis estromal necrotizante por virus herpes simple: A propósito de un caso. Archivo Sociedad Canaria de Oftalmología, 27, 20-23.

García, F. (2018). Queratitis por herpes simple: revisión de literatura. Revista de la Sociedad Colombiana de Oftalmología, 51(2), 105-114. 


\section{Etiología y factores de riesgo de la queratitis herpética}

Vol. 3, núm. 4., (2019)

Mariuxi Estefanía Macías Cedeño; Gabriela Ivonne Cedeño López; Shirley Johanna Arévalo Bravo; Martha Isabel Arcos Gutierrez

Harrison, D. A., \& Pagan, B. (01 de Marzo de 2016). ¿Qué es la queratitis herpética? Obtenido de Academia Americana de Oftalmología: https://www.aao.org/saludocular/enfermedades/queratitis-herpetica

Mayo Clinic. (05 de Febrero de 2019). Queratitis Diagnóstico. Obtenido de Mayo Clinic: https://www.mayoclinic.org/es-es/diseases-conditions/keratitis/diagnosis-treatment/drc20374114

Moya, R. E. (2015). Queratitis Epitelial Herpética. Ambato: Universidad Técnica de Ambato.

Muñoz, E., \& Morillo, B. (Noviembre de 2017). Infecciones por virus Herpes Simple. Obtenido de Asociación Española de Pediatría de Atención Primaria (AEPap): https://www.aepap.org/sites/default/files/documento/archivosadjuntos/infecciones_por_virus_herpes_simple_.pdf

Nijm, L. (25 de 11 de 2019). Herpes simple queratitis epitelial. Obtenido de Eyewiki: https://eyewiki.aao.org/Herpes_Simplex_Epithelial_Keratitis\#Etiology

Parro, M., Sánchez, M., Pueyo, C., Gómez de Salazar, E., Arnalich, F., \& Bermejo, T. (2018). Tratamiento de la queratitis herpética resistente a aciclovir y ganciclovir: a proposito de una serie de casos. Ofil-Ilapar, 28(4), 333-334.

Pérez, H. J. (2014). Establecimiento de una reacción en cadena de la polimerasa para la detección de bacterias y hongos. Revista Mexicana de Oftalmología, 88(2), 67-72.

Roat, M. (Agosto de 2018). Queratitis por herpes simple. Obtenido de Manual MDS: https://www.msdmanuals.com/es/professional/trastornos-

oft\%C3\%A1lmicos/enfermedades-de-la-c\%C3\%B3rnea/queratitis-por-herpes-simple

Servicio de Oftalmología del Hospital Universitario Sanitas La Moraleja. (30 de Abril de 2018). ¿Cómo se contagia la queratitis herpética? Obtenido de Sanitas: https://tusdudasdesalud.com/vision/enfermedades-ojo/queratitisherpetica/\#Tipos_de_queratitis_herpetica

Valverde, J. (Diciembre de 2017). Herpes virus. Dermatología Peruana, 27(4), 212-224. 
Etiología y factores de riesgo de la queratitis herpética

Vol. 3, núm. 4., (2019)

Mariuxi Estefanía Macías Cedeño; Gabriela Ivonne Cedeño López; Shirley Johanna Arévalo

Bravo; Martha Isabel Arcos Gutierrez

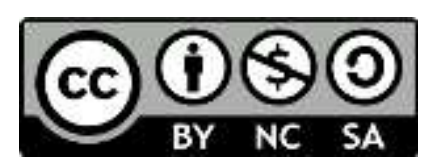

RECONOCIMIENTO-NOCOMERCIAL-COMPARTIRIGUAL

CC BY-NC-SA

ESTA LICENCIA PERMITE A OTROS ENTREMEZCLAR, AJUSTAR Y CONSTRUIR A PARTIR DE SU OBRA CON FINES NO

COMERCIALES, SIEMPRE Y CUANDO LE RECONOZCAN LA AUTORÍA Y SUS NUEVAS CREACIONES ESTÉN BAJO UNA LICENCIA CON LOS MISMOS TÉRMINOS. 